\title{
Os Valores Organizacionais e a Síndrome de Burnout: Dois Momentos em uma Maternidade Pública
}

\author{
Organizational Values and Burnout Syndrome: \\ Two Moments in a Public Day-care Center
}

\author{
Livia de Oliveira Borges, João Carlos Tenório Argolo, \& Maria Christina Santos Baker \\ Universidade Federal do Rio Grande do Norte
}

\begin{abstract}
Resumo
Estudos anteriores têm assinalado a associação da incidência da síndrome de burnoute os valores organizacionais (valores atribuídos às organizações pelos empregados em um nível ideal e real). Em tal contex to, foi desenvolvida pesquisa em uma maternidade pública em 2003, replicando uma pesquisa anterior realizada em 2000, objetivando comparar os resultados. Aplicaram-se o Inventário de Valores Organizacionais e o Inventário de Maslach sobre burnout, numa amostra de 48 profissionais de saúde, e entrevistas, numa sub-amostra. Os resultados indicaram ocorrer uma redução nas diferenças entre níveis de análise ideais e reais dos valores organizacionais, principalmente no pólo de igualitarismo. Esses resultados associam-se às mudanças na gestão organizacional. Os níveis de burnout entre os profissionais de saúde apresentaram-se estáveis. A associação entre os valores organizacionais da maternidade e a síndrome de burnoutmuda, porém é contraposta pela tensão oriunda no aumento da carga de trabalho e nos salários.

Palavras-chave: Valores, organizações; síndrome de burnout; análise de regressão; serviços de saúde.
\end{abstract}

\begin{abstract}
Previous studies have shown that the association between the incidence of Burnout Syndrome and organizational values (values attributed by employees to organizations on ideal and real levels). In this context, in 2003, a research at a public daycare center was developed, replicating a previous one accomplished in 2000, with the objective to compare the results. The Inventory of Organizational Values and the Maslasch Burnout Inventory were applied with the samples of 48 health professionals. Interviews were applied too. The results indicate that a reduction of differences between ideal and real levels of organizational values occur, notably in the equalitarian pole. These results associate to changes on organizational management. Levels of burnout were stable among heal th professionals. The association between organizational values of the day-care center and Burnout Syndrome change, but it is refuted by the tension from issues concerning the increase of workload and wages.

Keywords: Values; organizations; Burnout Syndrome; regression analysis; health service.
\end{abstract}

Mudanças na estrutura do sistema produtivo têm tornado as organizações mais complexas e repercutido nas relações de trabalho, implicando mais instabilidade nos empregos e renovando velhas angústias daqueles que trabalham. A lógica do produzir mais com menos recursos não é nova, porém sua revalorização é cada vez mais assimilada. Há, também, uma tendência a esperar mais adaptação do trabalhador à produção, por meio de mudanças como o desenho de cargos com atribuições mais variadas e mais complexas, de estruturas menos hierarquizadas e de maior atenção à relação do trabalhador ao usuário.

Essas configurações organizacionais têm demandado, em diferentes graus e por entre os diversos setores produtivos, novas exigências de qualidade na execução das tarefas, mais qualificação e novas competências do trabalhador. Tais demandas incidem particularmente no setor de serviços, face às suas peculiaridades, como o caráter direto do relacionamento do trabalhador com o cliente ou usuário e a diversidade das informações.

${ }^{1}$ Apoio: CNPq (Bolsa produtividade de L.O. Borges) e Programa de extensão de Psicologia Organizacional (UFRN).

${ }^{2}$ Endereço: $\mathrm{Dpt}^{\mathrm{o}}$. Psicologia, Centro de Ciências Humanas, Letras e Artes, UFRN, Natal, RN, 59078 970, Cx. Postal 1622. liviab@digi.com.br
Essas demandas são ainda maiores nos serviços de saúde em decorrência da ênfase na nobreza da missão dessas organizações e da busca por equacionar preceitos éticos e racionalidade técnica (Santana, 2001). Além disso, os serviços de atenção à saúde guardam especificidades relativas ao trato com a dor, ao sofrimento e ao mal-estar orgânico, emocional e social das pessoas. Portanto, requerem dos profissionais uma carga adicional de competências interpessoais, além das condições inerentes ao exercício profissional que incluem trabalho em turnos e escalas com for tes pressões externas.

No serviço de atenção à saúde, as características assinaladas ampliam-se quando delimitadas na esfera do setor público. As dificuldades estruturais são retratadas no cotidiano da sociedade brasileira, principalmente no que concerne à visão do usuário, mas também afetam os profissionais de saúde, visto que eles são obrigados a conviver com tais dificuldades e, muitas vezes, até serem responsabilizados pelas mesmas.

Desse modo, à dificuldade por equacionar princípios e técnicas, acrescenta-se o dever em cumprir os princípios do Sistema Único de Saúde (SUS). Logo, os profissionais de saúde do setor público, geralmente, são exigidos quanto ao 
enfrentamento de questões técnicas e sociais, sem eles disponham, contudo, dos recursos adequados.

Se a instituição pública de saúde está inserida no contexto universitário, adiciona-se outra peculiaridade, assume dupla missão: instituição assistencial e, ao mesmo tempo, acadêmica. A instituição depara-se com o acompanhamento simultâneo dos ministérios da saúde e da educação.

O hospital objeto do presente estudo - Maternidade Escola Januário Cicco (MEJC) - foi fundado em 1928, com fins originariamente filantrópicos, e incorporado à Universidade Federal do Rio do Grande do Norte (UFRN) em 1961. A MEJC, além de pioneira, é unidade hospitalar de referência no estado, sendo considerada competente, pelo SUS, para procedimentos técnicos de ginecologia e obstetrícia de média e alta complexidade. No entanto, acumula atendimentos ambulatoriais e procedimentos de baixa complexidade, os quais deveriam ser contemplados nas unidades de atenção primária.

A expressão da necessidade por mudanças, nesse hospital, efetivou-se, em julho de 2000, na solicitação de execução de um diagnóstico organizacional que buscasse identificar ações para superação de dificuldades e para o desenvolvimento institucional. As principais queixas referiam-se a problemas relacionais entre os servidores e entre esses servidores e suas chefias, à sobrecarga de trabalho e à fraca motivação dos profissionais.

Foi realizado um primeiro diagnóstico organizacional da MEJC, por meio de entrevistas com a direção geral e chefes de setores, observações do funcionamento dos setores e pesquisa documental de planejamentos, relatórios de avaliação institucional e aplicação de questionários nos profissionais de saúde. O referido diagnóstico investigou a relação entre os valores organizacionais e a síndrome de burnout, e integrou, posteriormente, um estudo comparativo em três hospitais universitários do estado do Rio Grande do Norte (Borges, Argolo, Machado, Pereira, \& Silva, 2002). Tal diagnóstico identificou a existência de conflitos entre os valores organizacionais que os profissionais de saúde acreditam que a MEJC deve assumir e os que percebem serem postos em prática no que diz respeito ao igualitarismo, autonomia e harmonia. Identificou também a incidência da síndrome de burnout e a associação desta aos conflitos de valores, corroborando estudo anterior (Tamayo, 1997) em hospitais de Brasília.

Aquele diagnóstico (Borges et al., 2002), na sua fase devolutiva, recomendou um conjunto de medidas a serem adotadas. Salienta-se que, à época daquele diagnóstico, o mandato da direção, que é de quarenta e oito meses, encontrava-se no $13^{\circ}$ mês. Decorridos 33 meses após o primeiro diagnóstico, a direção da MEJC solicitou um novo diagnóstico a fim de saber se houvera alguma modificação em relação ao anterior. Realizado o novo diagnóstico, surgiu a oportunidade de estabelecer um quadro comparativo entre os dois momentos da organização, no tocante à associação entre os valores organizacionais e a síndrome de burnout, configurando-se o objetivo do presente artigo. Por isso, na seqüência será sintetizada a revisão de literatura sobre os dois construtos referido.

\section{Valores Organizacionais}

A partir das investigações acerca dos valores humanos e fundamentando-se na estrutura dos valores culturais (Schwartz \& Ros, 1995), Tamayo et al. (Ex.: Tamayo, 1996; Tamayo \& Gondim, 1996; Tamayo, Mendes, \& Paz, 2000) sistematizaram estudos sobre os valores organizacionais, entendendo-os como aqueles valores atribuídos a uma organização, e partiram da percepção dos empregados e/ou dos funcionários.

Assim, os valores organizacionais, em sua multiplicidade, estruturam-se em três dimensões bipolares (Figura 1): Conservação versus Autonomia, Hierarquia versus Igualitarismo e Harmonia versus Domínio. A organização desses valores em pólos é obtida por meio de agrupamento empírico ${ }^{1}$, conforme indicado, sinteticamente, na Tabela 1.

A percepção da organização pode ser analisada em dois níveis distintos: o real e o ideal. O nível real é a maneira como os trabalhadores percebem os valores concretamente reforçados pela organização, valores estes que orientam sua estrutura e funcionamento. O nível ideal, por sua vez, diz respeito aos valores que os funcionários crêem que a organização deva seguir. A diferença da medida entre esses níveis em cada pólo designa-se por descompensação axiológica.

\section{Síndrome de Burnout}

Adota-se aqui a perspectiva psicossocial, que toma a síndrome de burnout como um processo, no qual os aspectos do contexto de trabalho e interpessoais contribuem para o seu desenvolvimento. O conceito mais aceito, nesta perspectiva, é o adotado por Maslach e Jackson (cf. citado em Maslach, 1994), que define a referida síndrome como: "uma reação à tensão emocional crônica por tratar excessivamente com outros seres humanos, particularmente quando eles estão preocupados ou com problemas" (p.61).

A síndrome é caracterizada por três fatores: Exaustão Emocional, Diminuição da Realização Pessoal e Despersonalização (Maslach, 1994; Maslasch, Schaufeli \& Leiter, 2001). O primeiro fator refere-se a sentimentos de fadiga e à redução dos recursos emocionais para lidar com a situação estressora. O segundo refere-se à percepção de deterioração da competência em resolver os problemas e da satisfação com as realizações no trabalho. O terceiro componente refere-se a atitudes negativas, ao ceticismo e à insensibilidade com respeito a outras pessoas, especialmente os usuários dos serviços prestados pelo profissional. Este último fator foi designado recentemente (Maslasch et al., 2001; Maslasch \& Leiter, 1999) por cinismo. Entretanto, será mantida a primeira designação aqui, porque o presente estudo foi desenvolvido utilizando instrumento de medida

${ }^{1}$ Estes agrupamentos se fundamentam em uma série de estudos empíricos (Schwartz \& Ros, 1995; Ros \& Schwartz, 1995) desenvolvidos em 40 nações, usando a técnica estatística SSA (Smallest Space Analysis) 
Borges, L.O., Argolo, J.C.T., \& Baker, M.C.S. (2006). Os Valores Organizacionais e a Síndrome de Burnout: Dois Momentos em uma Maternidade Pública.

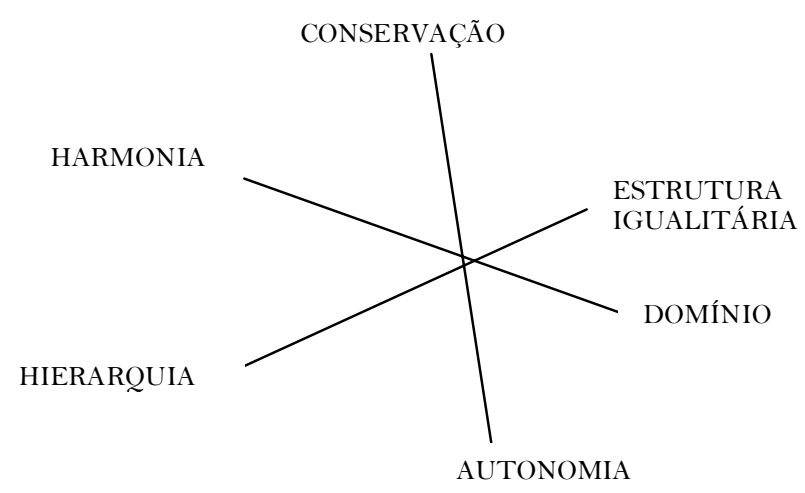

Figura 1. Dimensões bipolares dos valores organizacionais

elaborado a partir da primeira conceituação do fator.

A síndrome é compreendida como processo dinâmico, que se estabelece gradualmente, sendo por conseqüência possível identificar a apresentação da síndrome em níveis distintos. Gil-Monte e Peiró (1997) descrevem uma série de pesquisas desenvolvidas explorando a evolução da síndrome e defendem o modelo de Gil-Monte, Peiró, e Valcárcel (1995, citado em Gil-Monte \& Peiró, 1997), no qual o processo se inicia com o desenvolvimento dos sentimentos de baixa realização pessoal e exaustão emocional em paralelo. Posteriormente, instala-se a despersonalização em resposta a ambos sentimentos, como uma estratégia defensiva.

Tamayo (1997), Lee e Ashforth (1996) e Gil-Monte e Peiró (1997) assinalam a intensificação dos estudos nos úl timos 15 anos, de forma que já acumula uma considerável tradição empírica, o que segundo Maslach et al. (2001) tem implicado em uma crescente sofisticação metodológica e das ferramentas estatísticas utilizadas.

Há convergências nos estudos em apontar uma incidência elevada de tal síndrome entre profissionais de saúde (Amorim, 2002; Benevides-Pereira, 2002a, 2002b; Benevides-Pereira \& Moreno-Jiménez, 2002; Gil-Monte \& Peiró, 1997; Tamayo, 1997), professores (Carlotto, 2002;
Codo, 1999; Silva \& Barboza, 2003) e policiais (Gil-Monte \& Peiró, 1997), caracterizando uma tendência de endemia, embora que não ocorra exclusivamente com tais profissionais. Borges et al. (2002), replicando o estudo de Tamayo (1997) em hospitais públicos, levantaram a primeira evidência da incidência da síndrome entre profissionais de saúde em Natal.

Muito também há se estudado sobre seus determinantes para possibilitar o desenvolvimento e seleção adequada de estratégia de prevenção e de enfrentamento do problema. O número de aspectos e/ou fatores que se associam à ocorrência da referida síndrome são tantos que Gil-Monte e Peiró (1997) classificam as variáveis antecedentes em desencadeantes e facilitadores. Por desencadeantes, os autores identificam aqueles estressores com um caráter crônico que ocorrem no ambiente de trabalho. Por facilitadores, os autores designam características pessoais dos indivíduos que ampliam a suscetibilidade do indivíduo a apresentar sintomas da referida síndrome. Maslach e Leiter (1999) atentam para a importância de optar por estratégias preventivas centradas nos aspectos organizacionais. Por isso desenvolvem um modelo de intervenção, focalizando três tipos de antecedentes ambientais/organizacionais: (1) processos e estruturas de administração (supervisão, avaliação de desempenho, saúde e segurança); (2) seis áreas da vida organizacional (carga de trabalho, controle, remuneração, união, eqüidade e valores); e, (3) o compromisso com o trabalho (energia, envolvimento e eficiência).

Concernente com a abordagem de Maslach e Leiter (1999), Tamayo (1997) revelou associações da incidência da síndrome com valores organizacionais (amostra com enfermeiros e auxiliares de enfermagem de dois hospitais de Brasília). Encontrou relação positiva entre Diminuição da Realização Pessoal e os escores nos pólos axiológicos reais de Domínio e Harmonia e com os escores dos pólos axiológicos ideais de Autonomia e Conservação. Encontrou também que quanto maior o desejo de autonomia e igualdade

Tabela 1

Agrupamento dos Valores por Pólos Axiológicos

\begin{tabular}{|c|c|}
\hline Pólos axiológicos & Valores \\
\hline Autonomia & $\begin{array}{l}\text { Criatividade, curiosidade, eficiência, eficácia, modernização, qualidade, reconhecimento, competência, } \\
\text { prazer, inovação, realização, estimulação e liberdade. }\end{array}$ \\
\hline Conservação & Disciplina, honestidade, lealdade, limpeza, ordem, polidez, prestígio, segurança, sensatez e sigilo. \\
\hline Estrutura Igualitária & $\begin{array}{l}\text { Democracia, descentralização, justiça, qualificação dos recursos humanos, sociabilidade, co-gestão, } \\
\text { coleguismo, igualdade, cooperação, dinamismo, independência, autonomia, comunicação, respeito } \\
\text { e equidade. }\end{array}$ \\
\hline Hierarquia & Fiscalização, hierarquia, obediência, poder, pontualidade, rigidez, supervisão, tradição e autoridade. \\
\hline Harmonia & $\begin{array}{l}\text { Integração interorganizacional, interdependência, ética, parceria, tolerância, intercâmbio, } \\
\text { preservação, equilíbrio, respeito à natureza, espontaneidade, iniciativa. }\end{array}$ \\
\hline Domínio & $\begin{array}{l}\text { Ambição, audácia, competitividade, domínio, previsibilidade, produtividade, satisfação dos clientes e } \\
\text { sucesso. }\end{array}$ \\
\hline
\end{tabular}


maior a Exaustão Emocional. A réplica deste estudo em Natal (Borges et al., 2002) corroborou existir relações entre as duas variáveis, mas permutando os pólos axiológicos e fatores da síndrome entre instituições. Em relação à MEJC, encontrou-se que os escores de Despersonalização são previstos pelos escores no pólo real de Conservação.

\section{Método}

A presente pesquisa de campo foi desenvolvida tendo em vista comparar dois momentos distintos da vida da MEJC, como foi referido anteriormente, orientando-se pelas seguintes questões de pesquisa:

- A relação entre síndrome de burnoute valores organizações se mantém entre profissionais de saúde da maternidade?;

- Que mudanças ocorreram na gestão da MEJC entre os dois momentos (setembro/2000 a maio/2003)?;

- As prioridades e descompensações axiológicas, os escores médios nos fatores de burnout e a incidência da síndrome mantêm-se nos profissionais de saúde ?; e,

- As relações existentes entre as prioridades axiológicas e os escores nos fatores da síndrome de burnout foram mantidas?

Para responder adequadamente a tais questões, foram levantadas informações por meio de várias fontes, combinando técnicas de coleta de dados.

\section{População e Amostra}

Durante a realização do primeiro diagnóstico (2000), a população de profissionais de saúde do quadro efetivo era de 202 pessoas, das quais se formou uma amostra acidental, estratificada pelos diversos setores, de 60 funcionários. No segundo diagnóstico (2003), a mesma população era de 206 profissionais de saúde, destes formou-se uma amostra de 48 funcionários. A pesquisa restringiu-se aos funcionários efetivos, pois têm uma história de relacionamento mais contínuo com a organização. Além disso, os não-efetivos mais freqüentemente vivenciam múltiplos vínculos empregatícios.

Não se adotou nenhum controle sobre a repetição ou não dos participantes entre as duas amostras, ainda que um delineamento de pesquisa no qual se compararia o mesmo grupo de participantes em dois momentos seria superior para os objetivos do estudo. Optou-se por garantir o anonimato dos participantes ao responderem aos questionários. Esta prática objetiva proteger os participantes, criando condições favoráveis à autenticidade das respostas e, nesta pesquisa, importa mais porque o questionário sobre a síndrome de burnout inclui itens opostos à desejabilidade social.

\section{Instrumentos}

Foram utilizados dois questionários estruturados - o Inventário de Burnout de Maslach (MBI) e o Inventário de Valores Organizacionais (IVO) -, uma ficha sociodemográfica e um roteiro semi-estruturado de entrevista. O MBI, de autoria de Maslach e Jackson (1986), foi aplicado segundo a versão traduzida e validada por
Tamayo (1997), e depois revalidada com uma amostra de profissionais de saúde de várias instituições (hospitais e unidades básicas de saúde) em Natal (Tamayo, Argolo, \& Borges, 2005). Este questionário é composto de 22 itens, os quais os indivíduos devem responder indicando a freqüência em que ocorre o conteúdo sugerido no item (escala de 1 a 5). Mensura a síndrome em 3 fatores: Exaustão Emocional (alpha=0,84), Diminuição da Realização Pessoal (alpha=0,73) e Despersonalização (alpha=0,76) é de autoria de Tamayo e Gondim (1996) e compõe-se de 66 itens, os quais medem os valores organizacionais segundo os seis pólos axiológicos já citados - Conservação versus Autonomia, Hierarquia versus Igualitarismo e Harmonia versus Domínio - nos dois planos de análise: real e ideal.

Utilizou-se também uma ficha para levantamento de características sociodemográficas. Essa ficha, no segundo momento da pesquisa (2003), foi complementada com itens sócio-ocupacionais (tempo de serviço, carga horária etc.).

O roteiro de entrevista abrange duas questões: uma relacionada aos sentimentos dos funcionários acerca do seu trabalho na maternidade, e a outra, à percepção dos mesmos sobre a MEJC.

\section{Coleta de Dados}

A coleta de dados em ambos estudos foi feita por estudantes de graduação, sob a orientação dos pesquisadores. A aplicação dos questionários ocorreu na própria maternidade, individualmente, observando as conveniências de horário dos profissionais.

As entrevistas foram realizadas, em ambos momentos (2000 e 2003), com uma sub-amostra de forma que aconteciam após o preenchimento dos questionários. Em 2000, foram entrevistados 12 profissionais e, em 2003, 16 profissionais. A escolha dos profissionais a serem entrevistados considerava a distribuição dos mesmos por setor e por especialidade bem como a disposição dos mesmos em conceder a entrevista.

\section{Análise dos Dados}

As respostas aos questionários e à ficha de características sociodemográficas foram registradas na forma de banco de dados do programa estatístico Statistical Package for Social Science for Windows (SPSS). A partir das rotinas de tal programa, foram estimados os escores nos fatores da síndrome de burnout e nos pólos axiológicos reais e ideais bem como desenvolveram-se as análises estatísticas descritas paulatinamente na seção subseqüente.

Para caracterizar a instituição, consideraram-se os conteúdos dos documentos, dos depoimentos dos dirigentes nos diversos contatos para delimitação do trabalho a ser realizado e da observação assistemática dos estudantes durante as visitas à instituição para aplicação dos questionários. As respostas às entrevistas foram categorizadas e, em seguida, submetidas à análise de freqüência. 
Borges, L.O., Argolo, J.C.T., \& Baker, M.C.S. (2006). Os Valores Organizacionais e a Síndrome de Burnout: Dois Momentos em uma Maternidade Pública.

Tabela 2

Média dos Escores dos Pólos e Descompensação Axiológica nas Amostras de 2000 e 2003

\begin{tabular}{|c|c|c|c|c|c|c|c|c|}
\hline \multirow{2}{*}{ Pólos axiológicos } & \multicolumn{2}{|c|}{ Dimensão ideal } & \multicolumn{2}{|c|}{ Dimensão real } & \multicolumn{2}{|c|}{ Descompensação axiológica } & \multicolumn{2}{|c|}{ Teste $\mathrm{t}$} \\
\hline & 2000 & 2003 & 2000 & 2003 & 2000 & 2003 & $\mathrm{t}$ & $\mathrm{p}$ \\
\hline Conservação & 5,3 & 5,2 & 4,0 & 4,4 & 1,3 & 0,8 & 2,1 & 0,035 \\
\hline Autonomia & 5,5 & 5,4 & 3,3 & 4,1 & 2,2 & 1,3 & 4,3 & 0,000 \\
\hline Hierarquia & 4,4 & 4,2 & 4,4 & 4,6 & 0,0 & $-0,3$ & 0,4 & 0,691 \\
\hline Igualitarismo & 5,2 & 5,1 & 2,5 & 3,4 & 2,8 & 1,6 & 4,5 & 0,000 \\
\hline Harmonia & 5,1 & 5,0 & 3,1 & 3,8 & 1,9 & 1,2 & 3,4 & 0,001 \\
\hline Domínio & 4,7 & 4,6 & 3,3 & 3,6 & 1,4 & 1,0 & 1,7 & 0,088 \\
\hline
\end{tabular}

\section{Resultados}

\section{Contexto Organizacional}

A história da MEJC de 53 de anos confunde-se à história dos profissionais de saúde no estado do Rio Grande do Norte, bem como do sistema de atenção à saúde pública e da formação dos profissionais da Obstetrícia e Tocoginecologia. Concernente a essa observação, nas falas de alguns entrevistados e nos contatos informais durante as visitas para aplicação de questionário, manifestava-se o orgulho de fazer parte daquela instituição.

A estruturação e o funcionamento do hospital basearamse, ao longo do tempo, em princípios de hierarquia, ordem e disciplina, assimilados pelos funcionários. As percepções da maternidade como uma mãe ou a própria casa associam-se a sentimentos nostálgicos dos tempos quando havia rígida apuração de freqüência ao trabalho e de identificação dos funcionários, assemelhando-se à organização militar, segundo a fala dos entrevistados.

Destaca-se também a percepção de que a maternidade está se modernizando, mas que isso tem trazido um acréscimo de trabalho. Do mesmo modo, os profissionais de saúde percebem que a maternidade extrapola suas finalidades precípuas - atendimento terciário e atividades acadêmicas - oferecendo serviços primários de saúde em seu ambulatório.

Os sentimentos mais freqüentes nas entrevistas dos profissionais em relação ao trabalho na instituição são de: desestímulo, sub-utilização, baixa realização profissional, desconfor to e insatisfação (60\% das respostas); prazer, realização e satisfação (40\% das respostas). As causas atribuídas a esses sentimentos giram em torno de questões estruturais, tais como políticas públicas federais, mas também se referem ao modelo de gestão adotado pela organização. Entre essas, as causas mais comuns são: fraca comunicação organizacional, estilo de liderança e desumanização (entendida como a desconsideração pelas necessidades dos profissionais no estabelecimento de medidas administrativas em todos os níveis ocupacionais). Predominam, portanto, explicações a partir de atribuições de causalidade externa, ou seja, dirigidas ao ambiente.

As sugestões para melhoria dos serviços mais freqüentes referem-se ao enfrentamento da desigualdade, aos canais de comunicação e de discussão no processo decisório, às melhores condições materiais de trabalho e, principalmente, ao reconhecimento do mérito. Salienta-se que não se constatou diferença dos conteúdos das entrevistas e da sua distribuição nos dois momentos de diagnóstico.

Em relação às recomendações sugeridas no primeiro diagnóstico, foi constatado que somente uma parte delas foi implementada, mas outras já estavam, à época do segundo diagnóstico (2003), em fase de encaminhamento, a saber:

- Medidas recomendadas e implementadas: intensificação e melhoria da comunicação organizacional para fins de tomada de decisão, valorizando os espaços coletivos de decisão como reuniões colegiadas por setor, por meio da democratização do acesso e circulação da informação; melhoria da sinalização dos espaços físicos; investimento na capacitação para competências interpessoais (preocupação concretizada na promoção de treinamentos específicos das habilidades necessárias ao desenvolvimento de tais competências); e redimensionamento do setor de recursos humanos; e,

- Medida recomendada em encaminhamento: contratação de especialista em Gestão de Recursos Humanos. A MEJC foi o único hospital da UFRN a oferecer vaga para tal cargo, no úl timo concurso para cargos técnico-administrativos (2003).

No tocante às medidas implementadas, acrescenta-se que os residentes foram instalados em melhores condições. É possível que tal medida tenha sido percebida pelos funcionários como um indicador de consideração humana a todos os níveis ocupacionais.

\section{Prioridades e descompensações axiológicas}

Estimados os escores nos pólos axiológicos, por meio da média entre os pontos atribuídos pelos indivíduos aos diversos itens que os compõem, constatou-se (Tabela 2) no estudo realizado, no ano 2000, que os participantes da amostra priorizam os pólos de Autonomia, de Conservação, de Igualitarismo e de Harmonia. Em um nível de importância mais baixo estão os pólos de Domínio e de Hierarquia. Exatamente a mesma ordem de priorização dos pólos axiológicos é observada no plano ideal a partir das respostas dos participantes da amostra de 2003. Isso significa que não houve mudanças no pensamento dos profissionais de saúde da maternidade sobre que valores ela deve perseguir. 
Nessa Tabela 2, observa-se que no plano real, as respostas dos participantes da amostra de 2000 indicam uma percepção de priorização da Hierarquia, seguido de Conservação. Em um segundo patamar de escores, ocorre a priorização de Domínio, de Autonomia e de Harmonia. Em um terceiro patamar de prioridade, por fim, está o pólo de Igualitarismo. A acentuada diferença de ordenação dos pólos nos dois planos de análise implicou elevadas descompensações axiológicas, principalmente de Igualitarismo, de Autonomia, de Harmonia e de Domínio. Em contrapartida, a descompensação no pólo de Hierarquia era nula. Isso significa que a primeira amostra de pesquisa percebia muita diferença entre o que devia ser praticado de igualitarismo e de autonomia e o que a organização de fato praticava, mas em compensação percebia que a organização praticava a hierarquia que devia. Existia, portanto, um desejo de mudar nas práticas de igualitarismo e de incentivo à autonomia, mas mantendo uma estrutura hierarquizada. É importante comentar que a valorização de hierarquia está enraizada na história da MEJC como relatado anteriormente, mas também é um traço compartilhado com outras instituições hospitalares. Tal valorização provavelmente está associada à natureza das atividades hospitalares, pois está implicada a necessidade de decisões rápidas e firmes principalmente diante de situações de urgência.

Em continuação do exame da Tabela 2, constata-se que os escores médios dos participantes da amostra de 2003, no plano real de análise, mudaram, sendo as maiores elevações nos escores de Igualitarismo e de Autonomia, depois nos escores de Harmonia e de Conservação. As descompensações estimadas para as duas amostras comprovam essa observação e o teste $t$, aplicado para avaliar as diferenças entre as descompensações médias das duas amostras, indica que a mudança ocorrida na leitura da realidade (plano real dos pólos axiológicos) foi estatisticamente significativa. Ocorreu ainda crescimento não-significativo nos escores médios no pólo de Domínio e no pólo de Hierarquia. Isso significa que a organização, aos olhos dos participantes da amostra de 2003, mudou sua cultura na direção desejada em 2000, pois que conseguiu crescer nas práticas de igualitarismo, de autonomia, de harmonia e de conservação sem abrir mão de práticas de hierarquia e domínio. As ações da gestão da MEJC entre os dois estudos foram, portanto, eficazes na promoção da mudança cultural.

Em ambos os estudos, as relações entre as prioridades e descompensações axiológicas e as características sociodemográficas foram exploradas, encontrando-se algumas correlações significativas e que não se mantém entre as duas amostras. Assim, registra-se que na amostra de 2000 havia correlação diretamente proporcional entre domínio e a renda dos participantes $(r=0,27 ; p<0,05)$ e entre idade e os escores nos pólos reais de igualitarismo $(r=0,24 ; p<0,05)$ e de autonomia $(r=0,27 ; p<0,05)$. Entende-se que essas correlações decresceram (deixando de ser significativas), porque como os escores nesses pólos cresceram, passaram a ter mais homogeneidade. Portanto, os escores nos pólos reais de igualitarismo e de autonomia cresceram principalmente entre os mais jovens.

$\mathrm{Na}$ resposta dos participantes da amostra de 2003, foi observada uma correlação inversamente proporcional entre os escores no pólo ideal de hierarquia e renda dos participantes, o que significa que, nesta amostra, as pessoas

Tabela 3

Médias nos Fatores de Burnout (2000 / 2003), Desvio-padrão e Teste $t$

\begin{tabular}{|c|c|c|c|c|c|c|}
\hline & \multicolumn{2}{|c|}{ Média } & \multicolumn{2}{|c|}{ Desvio-padrão } & \multicolumn{2}{|c|}{ Teste $\mathrm{t}$} \\
\hline & 2000 & 2003 & 2000 & 2003 & $\mathrm{t}$ & $\mathrm{p}$ \\
\hline $\begin{array}{l}\text { Fatores da síndrome de burnout } \\
\text { Exaustão emocional }\end{array}$ & 2,26 & 2,16 & 0,61 & 0,63 & 0,57 & 0,57 \\
\hline Diminuição da realização pessoal & 1,93 & 2,02 & 0,50 & 0,60 & $-0,98$ & 0,33 \\
\hline Despersonalização & 1,52 & 1,44 & 0,66 & 0,63 & 0,46 & 0,65 \\
\hline
\end{tabular}

Tabela 4

A Incidência da Síndrome de Burnout, segundo os Três Fatores Componentes

\begin{tabular}{|c|c|c|c|c|c|c|c|c|}
\hline & \multicolumn{7}{|c|}{ Configurações } & \multirow[b]{2}{*}{8} \\
\hline & 1 & 2 & 3 & 4 & 5 & 6 & 7 & \\
\hline \multicolumn{9}{|l|}{ Fatores } \\
\hline Exaustão Emocional & Médio & Médio & Médio & Alto & Médio & Alto & Alto & Alto \\
\hline Diminuição de Realização Pessoal & Médio & Médio & Alto & Médio & Alto & Médio & Alto & Alto \\
\hline Despersonalização & Médio & Alto & Médio & Médio & Alto & Alto & Médio & Alto \\
\hline Amostra $1-2000(9 / 60=15 \%)$ & 3 & - & - & 3 & - & 4 & - & - \\
\hline Amostra $2-2003(7 / 48=14,6 \%)$ & 2 & 1 & - & 2 & - & 2 & - & - \\
\hline
\end{tabular}


Borges, L.O., Argolo, J.C.T., \& Baker, M.C.S. (2006). Os Valores Organizacionais e a Síndrome de Burnout: Dois Momentos em uma Maternidade Pública.

as quais mais defendem a valorização da hierarquia são também quem declara ter menor renda.

Os escores nos fatores da síndrome de burnout e a incidência da sindrome

Os escores nos fatores da síndrome de burnout-Exaustão Emocional, Diminuição da Realização Pessoal e Despersonalização - dos indivíduos de ambas as amostras foram calculadas por meio das médias aritméticas dos pontos atribuídos (escala de 1 a 5) às respostas a cada item que compõem os fatores citados. Constatou-se (Tabela 3) que as médias dos escores em todos os fatores da síndrome na MEJC foram mantidas com magnitudes aproximadamente iguais. A aplicação do teste $t$ para avaliar a diferença das médias entre as duas amostras, à medida que resultou em coeficientes que não são estatisticamente significativos, comprova tal constatação.

As respostas que os indivíduos apresentam aos itens do MBI não são isentas da influência que a cultura exerce no sentido de definir o que é desejável, por isso, na avaliação dos escores nos fatores, estes não podem ser classificados em al tos, moderados e baixos em função exclusiva da amplitude da escala (de 1 a 5), mas levando em conta o padrão de respostas da própria amostra. Isso significa dizer que a média da amostra em despersonalização mesmo sendo 1,93, numa escala de 1 a 5 , e estando muito distante do escore máximo, não é necessariamente baixa. Por isso que, desde Maslach e Jackson (1986), se utilizam os percentis que dividem a amostra nos escores de cada fator em três partes iguais como critério.

Em decorrência dos objetivos da presente análise implicar a comparação entre duas amostras, adotaram-se como critério os percentis utilizados no primeiro estudo (Borges et al., 2000). Feita, então, a classificação dos escores nos três fatores, levantou-se a ocorrência das 27 combinações possíveis, por meio da aplicação de análise de clusters. $\mathrm{Na}$ Tabela 4, estão as oito configurações previstas entre escores al tos e médios, representando a síndrome em seus níveis mais avançados de desenvolvimento. Observa-se, então, que as proporções dos indivíduos nas duas amostras com tal situação são aproximadamente iguais (15\% e 14,6\%, respectivamente), além de que apenas um indivíduo apresenta em 2003 uma configuração da síndrome (Exaustão Emocional média, Diminuição da Realização Pessoal média e Despersonalização alta) que não havia em 2000.

Tabela 5

Configurações que Mesclam Escores Altos, Médios e Baixos dos Fatores da Síndrome de Burnout

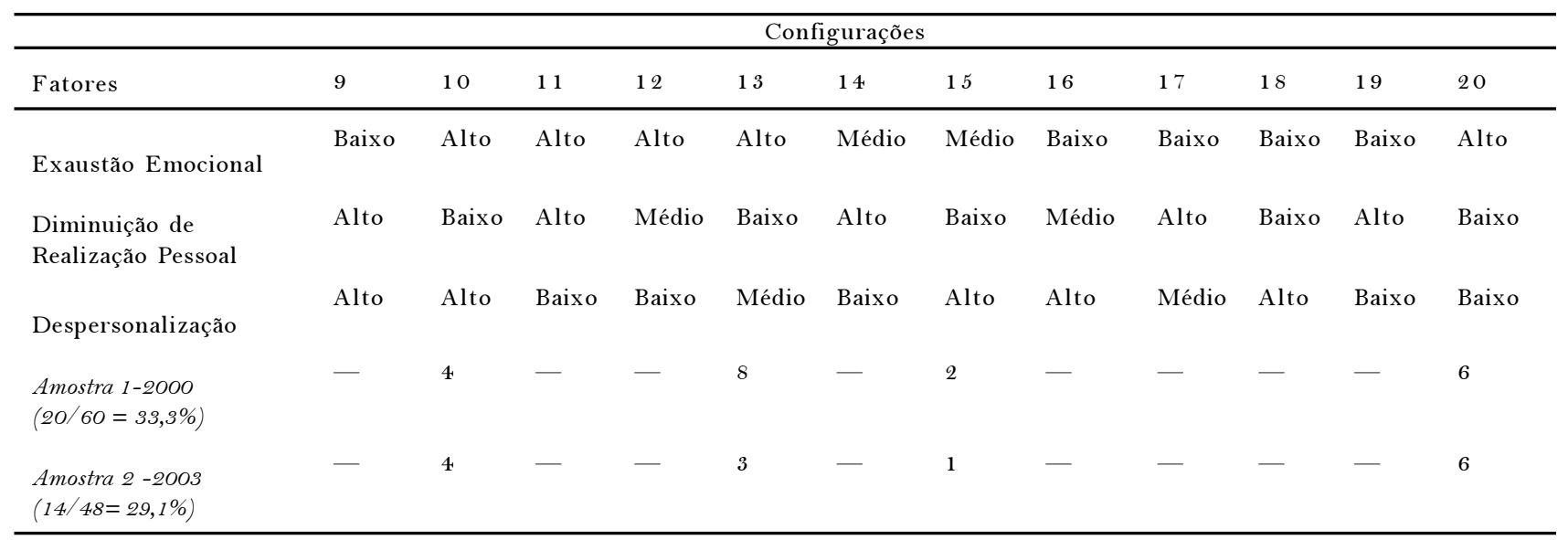

Tabela 6

Configurações que Mesclam Escores Médios e Baixos da Síndrome de Burnout

\begin{tabular}{|c|c|c|c|c|c|c|c|}
\hline \multirow[b]{2}{*}{ Fatores } & \multicolumn{6}{|c|}{ Configurações } & \multirow[b]{2}{*}{27} \\
\hline & 21 & 12 & 23 & 24 & 25 & 26 & \\
\hline Exaustão Emocional & Médio & Médio & Baixo & Baixo & Baixo & Médio & Baixo \\
\hline $\begin{array}{l}\text { Diminuição de } \\
\text { Realização Pessoal }\end{array}$ & Médio & Baixo & Médio & Baixo & Médio & Baixo & Baixo \\
\hline Despersonalização & Baixo & Médio & Médio & Médio & Baixo & Baixo & Baixo \\
\hline $\begin{array}{l}\text { Amostra } 1-2000 \\
(20 / 60=33,3 \%)\end{array}$ & - & 6 & 1 & 2 & 1 & 5 & 15 \\
\hline \multicolumn{8}{|l|}{ Amostra $2-2003$} \\
\hline$(14 / 48=29,1 \%)$ & 1 & 3 & 1 & 4 & 1 & 9 & 8 \\
\hline
\end{tabular}


Na Tabela 5, por sua vez, observam-se configurações que combinam escores dos três níveis (alto, médio e baixo). Essas configurações representam a síndrome em um estágio de evolução mais atenuado em comparação às configurações apresentadas na Tabela 4 ou alterações psíquicas diversas da síndrome de burnout. Embora pesquisas (Ex.: Moura, Argolo \& Borges, 2005) apontem outras endemias entre profissionais de saúde como tendências depressivas, as configurações encontradas sugerem mais uma tendência a apresentar a síndrome de burnout embora ainda não estabelecida. As proporções das duas amostras em tais configurações são semelhantes $(33,3 \%$ e $29,1 \%$ respectivamente) e são as mesmas configurações se repetem nas duas amostras.

As sete configurações que combinam escores médios e baixos representam as articulações entre os escores nos três fatores daqueles que convivem com a situação sem apresentar síndrome de burnout ou apresentando-a em nível bastante atenuado (Tabela 6). As proporções das amostras que apresentam tais configurações também são bastante semelhantes ( $50 \%$ e $56,3 \%$ respectivamente). Destaca-se que as maiores freqüências de participantes ocorrem nas duas configurações mais leves (configurações 26 e 27).

Esses resultados apontam que a incidência da síndrome de burnout nas duas amostras permaneceu inalterada. O olhar rápido nas Tabelas 4 a 6 pode conduzir a impressão que houve redução da incidência da síndrome, mas deve ser considerado que a segunda amostra é menor. Os percentuais dos participantes em cada tipo de configurações demonstram claramente que as proporções são aproximadamente iguais. A aplicação do qui-quadrado de Pearson para avaliar a dependência entre as distribuições dos participantes por tipos de configurações e por amostras corrobora a observação porque o coeficiente resultante não é estatisticamente significativo (qui-quadrado $=0,42 ; p=0,81$ ), indicando não rejeitar a independência entre as distribuições.

Comparando-se aos resultados de outros estudos no Brasil, observa-se que as médias de Exaustão Emocional e Diminuição da Realização Pessoal são levemente mais elevadas que aquelas encontradas por Tamayo (1997) em hospitais públicos de Brasília. Tais médias são praticamente iguais às encontradas por Tamayo et al. (2005) em outras instituições de saúde em Natal, apenas se observando que a média de Despersonalização na maternidade é levemente mais baixa.

A previsão dos escores nos fatores de burnout pelas prioridades e descompensações axiológicas

Desde o primeiro estudo, a relação entre a síndrome de burnout e as prioridades axiológicas está sendo explorada por meio de análises de regressão lineares (stepwise), nas quais os fatores da síndrome de burnout são tomados, um a um, como variáveis dependentes e os escores nos pólos axiológicos reais e ideais como variáveis independentes. No estudo realizado no ano 2000, os escores no pólo real de conservação previam os escores em Despersonalização de forma inversamente proporcional (beta=-0,28), numa regressão que explicava $8 \%$ da variância dos escores de Despersonalização. Repetindo-se as mesmas análises com a segunda amostra, foi encontrada uma regressão que explica $10 \%$ da variância dos escores do fator de Diminuição da Realização Pessoal, sendo que a variável preditora é desta vez os escores no pólo ideal de Hierarquia, numa relação diretamente proporcional (beta=0,32). Significa que, na amostra de 2003, aqueles que mais valorizam a hierarquia tendem a sofrer com a perda da realização pessoal.

Compreende-se que os resultados encontrados nos dois estudos sobre a relação entre valores organizacionais e o desenvolvimento da síndrome de burnout corroboram a inclusão dos valores entre os grandes blocos de aspectos do contex to ambiental das organizações que afetam o desgaste físico e emocional no trabalho (Maslach \& Leiter, 1999). No entanto, as presentes análises acrescentam que tal relação depende da configuração do conjunto de valores e/ou da cultura organizacional como um todo. Assim, no contexto de elevadas descompensações axiológicas (exceto no pólo de Hierarquia) - estudo de 2000 -, os escores em Conservação previam aqueles em Despersonalização. Em um contexto de percepção ascendente de Igualitarismo e de Autonomia entre outros pólos axiológicos - estudo de 2003 -, os escores no pólo ideal de Hierarquia prevêem aqueles referentes à Diminuição de Realização Pessoal. Lembra-se que, na teoria de valores culturais, Hierarquia e Igualitarismo são pólos de um mesmo eixo (Ros \& Schwartz, 1995; Schwartz \& Ros, 1995; Tamayo, 1996) e tal relação de oposição é a única da teoria que os estudos de cultura das organizações no Brasil têm comprovado ocorrer (Tamayo et al., 2000). Isso explica, pelo menos parcialmente, que as mudanças na cultura organizacional observadas na MEJC são vivenciadas com sofrimento, na forma de Diminuição de Realização Pessoal, para aqueles que mais consideram a hierarquia como um tipo de valor importante e necessário à instituição. Tais mudanças devem significar uma certa decepção com o "rumo" da instituição. Esse entendimento dos resultados é corroborado pelo saudosismo de tempos anteriores de uma história de gestões autoritárias, encontrado na fala dos entrevistados como foi registrado.

Essa compreensão da relação entre prioridades axiológicas e os escores nos fatores da síndrome de burnout, na qual as variáveis preditoras variam entre os pólos axiológicos na dependência do contex to cultural como um todo, é também corroborado por resultados encontrados em outras instituições hospitalares em Natal (Borges et al., 2002).

Mas, sobre a relação entre as prioridades axiológicas e a síndrome de burnout, além do que pôde ser elucidado pelas análises de regressão, é importante questionar a razão pela qual, tendo sido constatado mudança na percepção dos pólos axiológicos reais e nas descompensações axiológicas, a incidência da síndrome não foi reduzida.

Lembra-se que a síndrome de burnout apresenta um quadro complexo de determinantes, existindo inclusive classificações como a de Gil-Monte e Peiró (1997) que diferencia entre variáveis desencadeadoras e facilitadoras. Maslach e Leiter (1999) classificam as causas do ambiente 
Borges, L.O., Argolo, J.C.T., \& Baker, M.C.S. (2006). Os Valores Organizacionais e a Síndrome de Burnout: Dois Momentos em uma Maternidade Pública.

de trabalho (vida da organização) em seis blocos: carga de trabalho, controle, remuneração, união, eqüidade e valores. Esses blocos, por sua vez, são decorrentes dos processos e da estrutura de administração (missão, administração central, supervisão, comunicação, avaliação de desempenho, saúde e segurança). Por isso, no estudo de 2003, acrescentaram-se na ficha de características sociodemográficas, itens ocupacionais (tempo de profissão, tempo de instituição, carga horária de trabalho e renda em salários mínimos). Constatouse, então:

a) há correlações estatisticamente significativas da carga horária com os escores de Exaustão Emocional $(r=0,30)$ e com os escores em Despersonalização $(r=0,34)$. Ambas correlações são diretamente proporcionais, significando que os escores nos referidos fatores da síndrome de burnout crescem juntamente com a carga horária dedicada ao trabalho; e,

b) há correlação estatisticamente significativa e inversamente proporcional entre renda expressa em salários mínimos e os escores em Despersonalização ( $r=-0,31)$, indicando que quanto menor a renda do profissional, maior será a tendência a apresentar comportamentos de indiferença, desumanização do outro e ceticismo nas interrelações com o usuário e colegas de trabalho.

Constatadas essas correlações, as análises de regressão anteriormente realizadas foram repetidas, acrescentando entre as variáveis independentes: a carga de trabalho e a renda em salários mínimos. Observou-se, então, que apesar da correlação entre Exaustão Emocional e carga no trabalho, esta última não é capaz de prever a primeira. Quando se repetiu a regressão, tomando-se o fator Diminuição da Realização Pessoal como variável dependente acrescentando a carga de trabalho como variável independente, a equação que tinha os escores no pólo ideal de Hierarquia como preditor deixa de apresentar previsibilidade significativa da variável dependente. Esse fenômeno é designado por supressão (Abbad, 2002) e ocorre porque existe uma correlação entre hierarquia e renda, inversamente proporcional $(r=-0,35 ; p=0,03)$.

Quando a variável dependente é despersonalização, constata-se que renda prevê seus escores (beta= -0,35; $\left.r^{2}=0,12\right)$. Quando se insere carga de trabalho como variável independente, observa-se novamente o fenômeno da supressão e nenhuma variável independente prever significativamente Despersonalização. Ao repetir a análise de regressão, usando apenas carga de trabalho como variável independente, obtém-se uma equação explicando $11 \%$ da variância, na qual à carga de trabalho corresponde um coeficiente beta de 0,34.

Estes resultados permitem levantar que tendo havido mudança nas configurações dos valores, ampliando a compatibilidade entre os planos ideais e reais, não ocorreu queda na incidência de burnout porque, no mesmo período, houve aumento da carga de trabalho e da pressão sobre os salários em decorrência das políticas de contenção de despesas no setor público. Observa-se que esta compreensão é corroborada por conteúdos existentes nas falas dos entrevistados, relatando que a modernização da maternidade tem implicado em maior carga de trabalho. Além disso, a ampliação da participação e do igualitarismo, ao menos no início, implica um aumento de responsabilidades para aqueles que antes não tinham acesso ao processo decisório, ocorrendo um aumento qualitativo da carga de trabalho.

\section{Conclusões e Considerações Finais}

Sumariando os resultados apresentados, pode-se dizer que a MEJC está implementando ações que têm impacto na cultura organizacional, tornando mais compatível os níveis ideal e real de seus valores, principalmente no que se refere aos pólos axiológicos de igualitarismo e de autonomia. Esse resultado na cultura organizacional, por sua vez reduziu o impacto que a descompensação axiológica de desigualdade tinha sobre o fator de Despersonalização da síndrome de burnout, mas em compensação criou tensões, especialmente para os indivíduos que mais valorizam hierarquia, o que impacta na diminuição de realização pessoal. Além disso, o aumento de carga de trabalho ocorrido no período e a pressão salarial não permitiram uma queda na incidência da síndrome de burnout.

Em decorrência desses resultados, entende-se que o processo de mudança precisa avançar, tanto no sentido de ampliar mais ainda as compatibilidades entre valores ideais e reais, quanto criando ajustes nas práticas organizacionais para re-equilibrar a carga de trabalho. As políticas salariais precisam também de ajuste, o que, porém, não é da alçada da maternidade enquanto uma instituição pública federal. O fato de as médias nos fatores da síndrome de burnout serem aproximadamente iguais às médias de outras instituições públicas de saúde reforça a idéia de que existem aspectos conjunturais influenciando a incidência da síndrome. Devese considerar que o aumento de carga de trabalho e da pressão salarial são fenômenos que parecem se generalizar no serviço público nos úl timos anos. Tais tendências representam uma face do fenômeno que na introdução deste artigo foi referida como a revalorização da lógica do produzir mais com menos recursos. Além de que as mudanças observadas na MEJC representam as mesmas tendências comentadas na introdução deste artigo como genéricas ao mundo do trabalho atualmente, por exemplo: horizontalização do processo decisório, mais responsabilidades nos setores básicos e mais atenção à relação do trabalhador com o usuário.

Pelo que foi exposto, conclui-se que as análises relatadas atingiram os objetivos propostos, além de que a estratégia de comparar dois momentos da instituição revelou-se uma estratégia metodológica capaz de elucidar aspectos do processo que não seria possível na exploração de um momento isolado.

Novos diagnósticos da instituição, em momentos futuros, podem trazer a luz aspectos relevantes na compreensão da relação existente entre valores organizacionais e a síndrome de burnout em um contex to de mudanças, contribuindo para a construção do conhecimento. A discussão, na instituição, das análises relatadas neste artigo pode contribuir para uma 
melhor compreensão do seu processo de mudança, apoiando o seu direcionamento.

\section{Referências}

Abbad, G. (2002). Regressão múltipla stepriise e hierárquica em Psicologia Organizacional: aplicações, problemas e soluções. Estudos de Psicologia, 7( $\mathrm{N}^{\mathbf{o}}$ especial $), 19-30$.

Amorin, C. (2002). Síndrome de burnout em fisioterapeutas e acadêmicos de fisioterapia. In A.M.T. Benevides-Pereira (Ed.), Burnout: quando o trabalho ameaça o bem-estar do trabalhador (pp.93-104). São Paulo: Casa do Psicólogo.

Benevides-Pereira, A.M.T. (2002a). As atividades de enfermagem em hospital: um fator de vulnerabilidade ao burnout. In A.M.T. Benevides-Pereira (Ed.), Burnout: Quando o trabalho ameaça o bem-estar do trabalhador (pp.133-156). São Paulo: Casa do Psicólogo.

Benevides-Pereira, A.M.T. (2002b). O adoecer dos que se dedicam à cura das doenças. O burnout em um grupo de médicos. In A.M.T. Benevides-Pereira (Ed.), Burnout: quando o trabalho ameaça o bem-estar do trabalhador (pp. 105-132). São Paulo: Casa do Psicólogo.

Benevides-Pereira, A.M.T. \& Moreno-Jiménez, B. (2002). O burnout em um grupo de psicólogos brasileiros. In A.M.T. Benevides-Pereira (Ed.), Burnout: quando o trabalho ameaça o bem-estar do trabalhador (pp.157-186). São Paulo: Casa do Psicólogo.

Borges, L., Argolo, J.C.T., Pereira, A., Machado, A., \& Silva, W. (2002). A síndrome de burnout e os valores organizacionais: um estudo comparativo em hospitais universitários. Psicologia: Reflexão E Crítica, 15, 189-200.

Carlotto, M. S. (2002). Síndrome de burnout e a satisfação no trabalho: um estudo com professores universitários. In A.M.T. Benevides-Pereira (Ed.), Burnout: quando o trabalho ameaça o bem-estar do trabalhador (pp.187-212). São Paulo: Casa do Psicólogo.

Codo, W. (Ed.) (1999). Educação: trabalho e carinho. Petrópolis: Vozes.

Gil-Monte, P. \& Peiró, J. M. (1997). Desgaste psíquico en el trabajo: el Sindrome de Quemarse. Madrid: Síntesis.

Lee, R.T. \& Ashforth, B.E. (1996). A meta-analytic examination of correlates of the three dimensions of job burnout. Journal of Applied Psychology, 81, 123-133.

Maslach, C. (1994). Stress, burnout and workaholism. In R. Kilburg, P.E. Nathan, \& R.W. Thoreson (Eds.), Professionals in distress: issues, syndromes, and solutions in psychology (pp.53-75).

Washington: American Psychological Association.

Maslach, C. \& Jackson, S. (1986). Maslach Burnout Inventory
Manual. Palo Alto: Consulting Psychologist Press.

Maslach, C. \& Leiter, M. P. (1999). Trabalho: fonte de prazer ou desgaste? Campinas: Papirus.

Maslach, C., Schaufeli, W.B. \& Leiter, M. (2001). Job burnout. Annual Review of Psychology, 52, 397-422.

Moura, H.B.O., Borges, L.O. \& Argolo, J.C.T. (2005). Saúde mental dos que lidam com a saúde: os indicadores de Goldberg. In L.O. Borges (Ed.), Profissionais de saúde e seu trabalho (pp.). São Paulo: Casa do Psicólogo.

Ros, M. \& Schwartz, S.H. (1995). Jerarquía de valores en países de la Europa Occidental: una comparación transcultural. Revista Española de Investigaciones Sociológicas, 69, 69-87.

Santana, J.P. (2001). A gestão do trabalho nos estabelecimentos de saúde: elementos para uma proposta. (Disponível 22/10/2003, www.opas.org.br/rh/publicacoes/textos_apoio/ pubo4u3t6.pdf)

Schwartz, S. \& Ros, M. (1995). Values in the west. A theoretical and empirical challenge to the individualism-collectivism cultural dimension. World Psychology, I(2), 91-122.

Silva, W.R., \& Barboza, D.M. (2003). A síndrome de burnout em professores da Universidade Federal de Sergipe [Resumos] Em Universidade Federal da Paraíba, Conselho Regional de Psicologia (CRP-13), Centro Universitário de João Pessoa \& Universidade Estadual da Paraíba (Eds.), III Congresso NorteNordeste de Psicologia. Construindo a Psicologia Brasileira: Desafios da ciência e Prática Psicológica. Anais do congresso (Vol. I; pp.393-394). João Pessoa: UFPB/CRP-13.

Tamayo, A. (1996). Valores organizacionais. In A. Tamayo, J.E. Borges-Andrade \& W. Codo (Eds.), Trabalho, organizações e cultura (pp.157-172). São Paulo: Cooperativa de Autores Associados.

Tamayo, M.R. (1997). Relação entre a síndrome de burnout e os valores organizacionais no pessoal de enfermagem de dois hospitais públicos. Dissertação de Mestrado não-publicada, Universidade de Brasília. Brasília, DF.

Tamayo, M.R., Argolo, J.C., \& Borges, L.O. (2005). Burnout em profissionais de saúde: um estudo com trabalhadores do município de Natal. In L.O. Borges (Ed.), Profissionais de saúde e seu trabalho (pp.). São Paulo: Casa do Psicólogo.

Tamayo, A. \& Gondim, M.G.C. (1996). Escala de valores organizacionales. Revista de Administração, 31(2), 62-72.

Tamayo, A., Mendes, A.M., \& Paz, M.G.T. (2000). Inventário de valores organizacionais. Estudos de Psicologia(Natal), 5 , 289316.

Recebido: 27/02/2004 Ia revisão: 23/08/2004 $2^{a}$ revisão: $25 / 01 / 2005$ Aceite final: 14/02/2005 